Provided for non-commercial research and education use. Not for reproduction, distribution or commercial use.

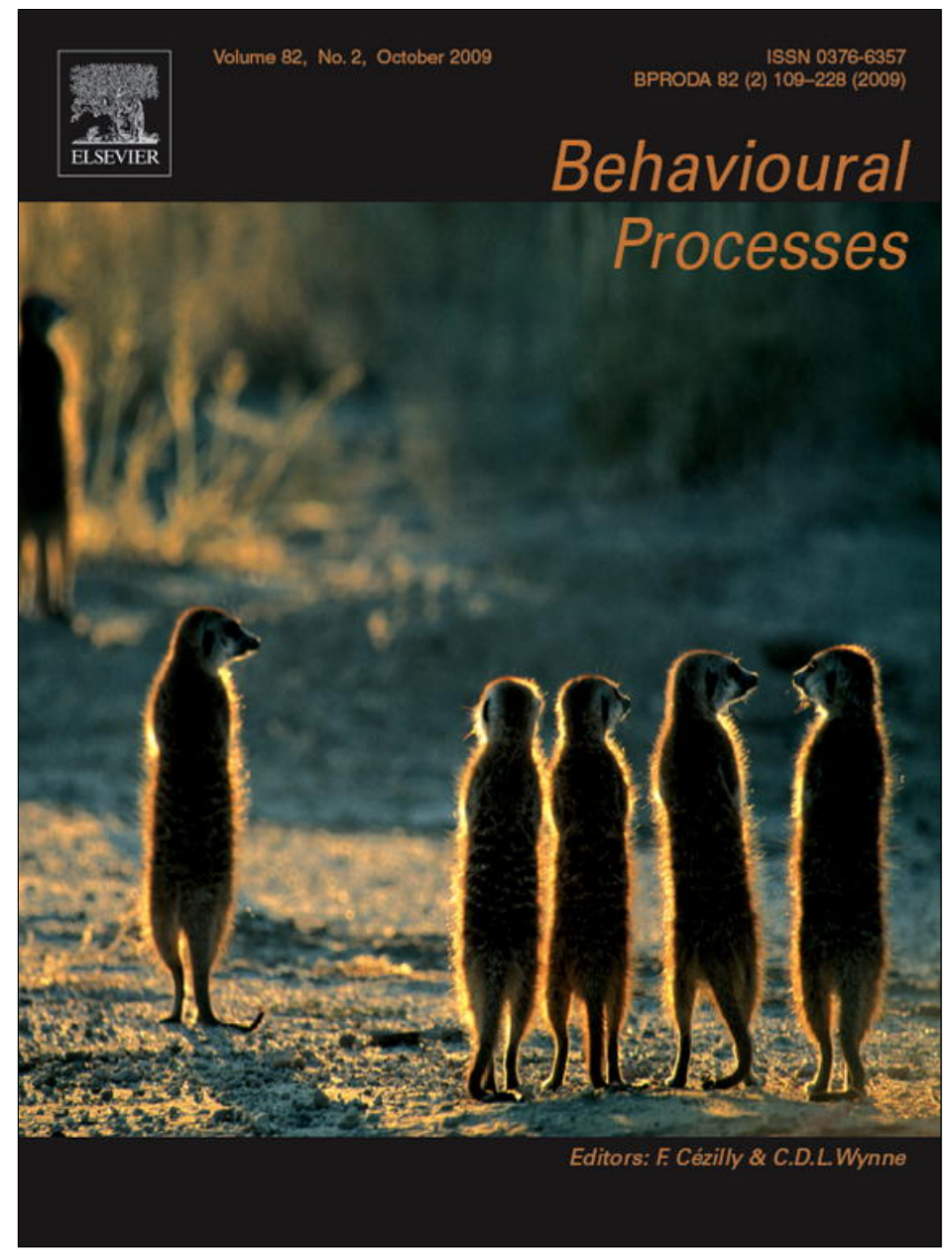

This article appeared in a journal published by Elsevier. The attached copy is furnished to the author for internal non-commercial research and education use, including for instruction at the authors institution and sharing with colleagues.

Other uses, including reproduction and distribution, or selling or licensing copies, or posting to personal, institutional or third party websites are prohibited.

In most cases authors are permitted to post their version of the article (e.g. in Word or Tex form) to their personal website or institutional repository. Authors requiring further information regarding Elsevier's archiving and manuscript policies are encouraged to visit:

http://www.elsevier.com/copyright 


\title{
Within-trial contrast: The effect of probability of reinforcement in training
}

\author{
Cassandra D. Gipson ${ }^{a}$, Holly C. Miller ${ }^{\mathrm{a}}$, Jérôme J.D. Alessandri ${ }^{\mathrm{b}}$, Thomas R. Zentall ${ }^{\mathrm{a}, *}$ \\ a University of Kentucky, United States \\ ${ }^{\mathrm{b}}$ Université de Lille III, France
}

\section{A R T I C L E I N F O}

\section{Article history:}

Received 3 March 2009

Received in revised form 11 May 2009

Accepted 21 May 2009

\section{Keywords:}

Within-trial contrast

Work ethic

Partial reinforcement

Simultaneous discrimination

Pigeons

\begin{abstract}
A B S T R A C T
There is evidence that pigeons prefer conditioned reinforcers that are preceded by greater effort over those that are preceded by less effort (an effect that has been attributed to within-trial contrast). In past research the probability of reinforcement for correct choice of the conditioned reinforcer has been $100 \%$, however, the high level of reinforcement for both alternatives in training may result in a performance ceiling when choice between those alternatives is provided on test trials. In the present study we tested this hypothesis by including a group for which the probability of reinforcement in training was only 50\%. Pigeons were trained on two simultaneous discriminations, one that was preceded by a 30 peck requirement the other by a single peck requirement. On test trials, we found a significant preference for the $S+$ that required the greater effort in training for pigeons trained with $100 \%$ and a small but nonsignificant effect for pigeons trained with 50\% reinforcement. Although the hypothesis that the within-trial contrast effect was constrained by a performance ceiling was not confirmed, we did find a reliable within-trial contrast effect with $100 \%$ reinforcement.
\end{abstract}

(c) 2009 Elsevier B.V. All rights reserved.
Within-trial contrast is a phenomenon reported by Clement et al. (2000) in which pigeons were trained on two simultaneous discriminations, each involving a pair of colors (e.g., red S+, yellow Sand green $S^{+}$, blue $S_{-}$). On half of the trials, pigeons had to peck a circle stimulus once, to obtain, for example, the red/yellow discrimination. On the remaining trials, they had to peck the circle 20 times to obtain the green/blue discrimination. On test trials, when the pigeons were given a choice between the two positive stimuli, they showed a significant preference for the stimulus that required 20 pecks to obtain. Clement et al. proposed that this counterintuitive effect resulted from contrast between the effort that preceded the discrimination and the conditioned reinforcement associated with the discrimination. That is, the value of the reinforcer (or the stimulus that predicted it) was greater when it was preceded by a less preferred event (see Zentall and Singer, 2007).

The results of several studies have shown not only that the effect can be replicated in pigeons (Clement and Zentall, 2002; Friedrich and Zentall, 2004), starlings (Kacelnik and Marsh, 2002 and humans (Alessandri et al., 2008a,b; Klein et al., 2005) but also that other less preferred events that precede a discrimination can produce a preference for the S+ stimulus that follows. For example, DiGian et al. (2004) found that a delay that preceded a discrimination increased

\footnotetext{
is This research was supported by National Institute of Mental Health Grant 63726 . * Corresponding author at: Department of Psychology, University of Kentucky, 500 South Limestone St., Lexington, KY 40506, United States. Tel.: +1 859257 4076; fax: +1 8593231979 .

E-mail address: zentall@uky.edu (T.R. Zentall).
}

the preference for the $\mathrm{S}+$ stimulus that followed and Friedrich et al. (2005) found that when the absence of food preceded a discrimination it increased the preference for the $\mathrm{S}+$ stimulus that followed (when on other trials a discrimination was preceded by the presentation of food). Similarly, Alessandri et al. (2008b) found that when the initial event required greater force to obtain the discrimination it increased the preference for the S+ stimulus that followed.

However, several studies have reported a failure to replicate the original finding with pigeons and the results of these studies may identify constraints on the effect. For example, Vasconcelos et al. (2007) presented the results of six experiments that failed to replicate the within-trial contrast effect. In each of these experiments the pigeons were given 20 sessions of training following the acquisition of the simultaneous discriminations. Although 20 session of overtraining is often enough to produce the effect (Clement et al., 2000; Clement and Zentall, 2002; DiGian et al., 2004; Friedrich et al., 2005), other research suggests that 20 sessions of overtraining is often insufficient (Friedrich and Zentall, 2004; Singer et al., 2007) and 30-60 sessions of overtraining may be needed.

But the amount overtraining does not appear to be the only important variable because other studies that included more extensive training have also failed to find significant within-trial contrast (Arantes and Grace, 2008, experiment 2; Vasconcelos and Urcuioli, 2008a). Arantes and Grace reported that although they failed to find a within-trial contrast effect, their overtrained pigeons had served as subjects in earlier research and although they do not provide details about the prior experience, it is quite likely that the schedules of reinforcement that they experienced were leaner that those experienced in the experiment reported. If so, it may be that prior 


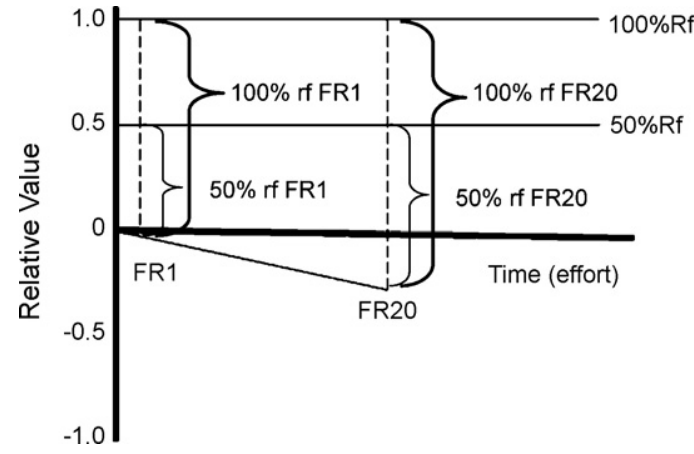

Fig. 1. A model of within-trial contrast. The value of reinforcement depends on the change in value between the negative state caused by pecking and the absolute value of reinforcement. Choice will depend on whichever change in value is larger.

experience with lean schedules of reinforcement reduces the contrast that can be found between the 20 peck requirement and the simultaneous discrimination (Zentall, 2008).

In the case of Vasconcelos and Urcuioli (2008a), five pigeons were trained for 60 sessions on a task similar to that used by Clement et al. (2000) and were similarly tested. Although these pigeons chose the $\mathrm{S}+$ that in training had followed the high effort ( 30 peck) requirement more than $60 \%$ of the time on the first test session, it was not significantly different from chance. But this level was not substantially lower than that reported by Clement et al. (69.2\%) and their failure to find a significant effect may be attributable to low power. More recently, Vasconcelos and Urcuioli (2009) attempted to obtain a within-trial contrast effect with experimentally naïve pigeon which were provided with 60 sessions of overtraining. But they too failed to replicate the within-trial contrast effect. However, Vasconcelos and Urcuioli gave their pigeons extensive pretraining ( 12 sessions) to work up to the 30 peck requirement. It may be that the gradual increase in response requirement reduced the aversiveness of the 30 peck requirement sufficiently to obscure the contrast effect.

Given the apparent variability in the magnitude of the withintrial contrast effect reported, it would be useful to replicate the within-trial contrast effect using a differential response requirement in the initial link and to identify variables that might enhance or diminish the effect. One variable that could affect the magnitude of within-trial contrast is the percentage of reinforcement associated with choice of the S+ stimulus in the simultaneous discrimination. In the Clement et al. (2000) experiment, preference was found not only for the S+ stimulus but also for the S- stimulus that followed the greater effort. Furthermore, the $\mathrm{S}$ - effect was larger than the $S+$ effect. Clement et al. suggested that the $S+$ preference may have been constrained by a ceiling effect. Given that both S+ stimuli were strongly associated with reinforcement, it is possible that the difference in value between them was reduced by their high absolute value. Such an effect could be produced either by the reduced discriminability between their two values or by the fact that because both had high value, the pigeons tended to respond to the first one that they saw. The hypothesis that the reduced choice of the $S+$ associated with higher effort resulted from a ceiling effect raises the possibility that a larger within-trial contrast effect might be seen if the probability of reinforcement for choice of the S+ stimulus in training were lowered to $50 \%$.

Another mechanism by which $50 \%$ reinforcement could produce a larger effect than $100 \%$ reinforcement is presented in Fig. 1. If choice of the S+ stimulus depends on the relative change in value that occurs at the time of reinforcement (or the appearance of the $\mathrm{S}+$ associated with reinforcement) then reducing the value of both stimuli through partial reinforcement could actually increase the relative difference in value between them. To get some sense for how this might occur, imagine for example, that the value of $100 \%$ reinforcement is 1.0 , the value of $50 \%$ reinforcement is 0.5 , the value of 1 peck is 0 , and the value of 20 pecks is -0.25 . With $100 \%$ reinforcement, the change in relative value on FR1 and FR20 trials would be 1.0 and 1.25 , respectively. That would mean that the relative value on the appearance of the FR20 associated S+ would be $25 \%$ greater than the relative value on the appearance of the FR1 associated S+. However, with 50\% reinforcement, the change in relative value on FR1 and FR20 trials would be 0.5 and 0.75 , respectively. That would mean that the relative value on the appearance FR20 associated $S+$ would be $50 \%$ greater than the relative value on the appearance of the FR1 associated S+. Thus, with 50\% reinforcement, the relative difference between the change in value when the S+ stimuli appeared (50\%) would be greater than with $100 \%$ reinforcement (25\%).

But the above argument assumes that it is the relative ratio of the change in value that determines the degree of stimulus preference. Alternatively, the choice of the S+ stimulus may depend on the absolute difference in the value of the two S+ stimuli. In that case, the reduction in value of the two $S+$ stimuli would be the same with $100 \%$ and $50 \%$ reinforcement and the magnitude of the within-trial contrast effect should not change.

A third possibility is that a threshold value must be exceeded before there is a contrast effect and $50 \%$ reinforcement is not sufficient to exceed that level. If that is the case, the amount of within-trial contrast actually may be reduced or eliminated by partial reinforcement.

In the present experiment we tested the hypothesis that the probability of reinforcement associated with the two S+ stimuli would affect the magnitude of the within-trial contrast effect. Pigeons were trained with a procedure very similar to Clement et al. (2000) except the response requirement for the higher effort schedule was increased from 20 to 30 pecks. For half of the pigeons, choice of the $\mathrm{S}+$ stimulus in each simultaneous discrimination was reinforced $100 \%$ of the time. For the remaining pigeons choice of the $\mathrm{S}+$ stimulus in each simultaneous discrimination was reinforced $50 \%$ of the time. Because Clement et al. (2000) trained their pigeons with $100 \%$ reinforcement but tested them with $50 \%$ reinforcement (nondifferentially) we tested half of the pigeons in each group with $100 \%$ reinforcement (regardless of their choice) and the remaining half of the pigeons with $50 \%$ reinforcement (regardless of their choice).

Finally, given that the results of several experiments have failed to replicate the results of Clement et al. (2000), a second purpose of the present experiment was to replicate their results using a somewhat larger difference in response requirement in the initial link (1 vs. 30 pecks rather than 1 vs. 20 pecks), an extended training procedure (more than 60 sessions of overtraining), and pigeons that did not have a prior history of lean schedules of reinforcement.

\section{Method}

\subsection{Subjects}

Sixteen White Carneau pigeons (Columba livia), retired breeders (5-8 years of age) that were purchased from the Palmetto Pigeon Plant (Sumter, SC) served as subjects. Pigeons were individually housed in wire cages and maintained at $85 \%$ of their free-feeding body weights for the duration of the experiment. Free access to water and grit was given in their home cages, and the pigeon colony room was maintained on a 12:12-h light/dark cycle, lights on at $0700 \mathrm{~h}$. The pigeons were cared for in accordance with the University of Kentucky animal care guidelines. All pigeons had previously served in an unrelated discrete-trial, conditional discrimination (matching-to-sample). 

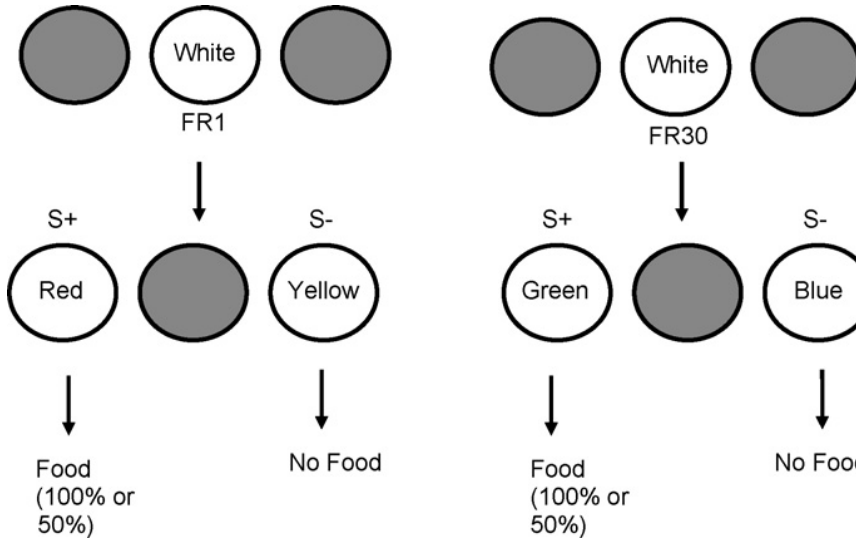

FR30
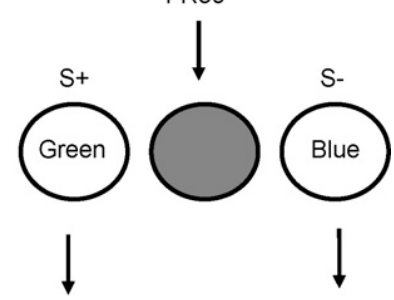

Food

$(100 \%$ or

$50 \%)$

No Food
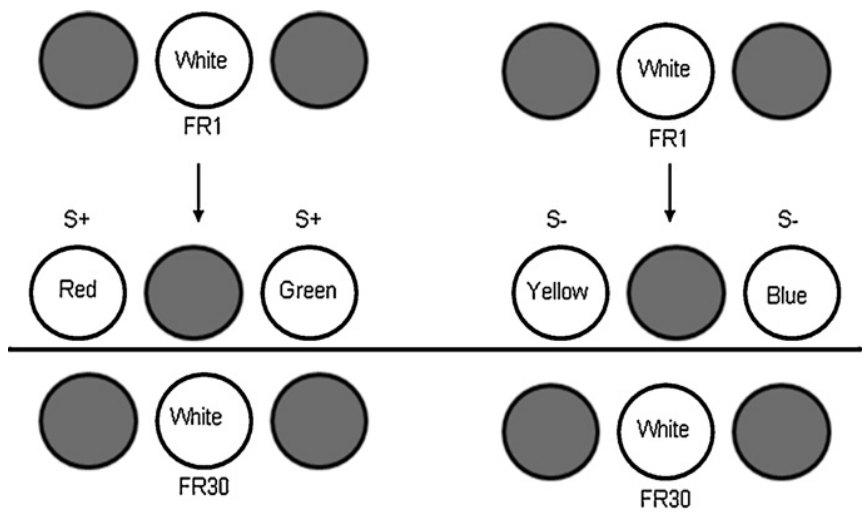

Fig. 2. A schematic of the two discriminations in training. Pigeons were required to peck either one or 30 times to the white center key. Two discriminative stimuli were then illuminated (S+ and S-). Responses to the S+ resulted in reinforcement $100 \%$ or $50 \%$ depending on the condition.

\subsection{Apparatus}

The experiment was conducted using a standard operant chamber (BRS/LVE, Laurel, MD). The chamber measured $32.0 \mathrm{~cm}$ high, $32.0 \mathrm{~cm}$ across the response panel, and $28.0 \mathrm{~cm}$ from the response panel to the back wall. Three round response keys $(2.5 \mathrm{~cm}$ in diameter) were aligned horizontally on the response panel and were separated by $0.8 \mathrm{~cm}$. All response keys were $24.1 \mathrm{~cm}$ from the floor of the operant chamber. A 12-stimulus in-line projector (Industrial Electronics Engineering, Van Nuys, CA) with $28 \mathrm{~V}, 0.1 \mathrm{~A}$ lamps (GE 1820) was mounted behind each response key. The center key projected a white (unfiltered) stimulus. The side keys projected red, green, yellow, or blue hues. An unfiltered houselight (GE 1820) mounted at the center top of the response panel was illuminated during the intertrial intervals (ITIs). A rear-mounted feeder provided mixed grain reinforcement (Purina Pro Grains) through a $5.1 \mathrm{~cm} \times 5.5 \mathrm{~cm}$ aperture centered horizontally on the response panel and vertically midway between the response keys and the floor of the chamber. Reinforcement consisted of 1.5-s access to mixed grain. An exhaust fan was mounted outside the chamber to mask extraneous noise. The experiment was controlled and data recorded by a microcomputer located in an adjacent room.

\subsection{Procedure}

\subsubsection{Pretraining}

Pigeons were initially trained to make a single response to the center white key to gain access to grain in the lit feeder. Following reinforcement, there was a 10-s ITI during which the houselight was illuminated. The pecking requirement gradually increased to 30 pecks (a fixed ratio, FR, 30). Once pigeons were responding consistently on an FR30 schedule they were moved into the training phase.

\subsubsection{Training}

Following pretraining, pigeons were trained on two schedules of reinforcement (see Fig. 2 for the design of training trials). Each schedule was initiated by the illumination of the center white key. Completion of the FR1 on the center white key was followed by the illumination on the side keys of red and yellow hues for half of the pigeons and green and blue hues for the remaining pigeons. Choice of the correct stimulus, S+ (counterbalanced for hue), with a single peck was followed by the ITI and reinforcement for half of the pigeons and reinforcement on half of the trials for the remaining pigeons. Choice of the incorrect stimulus, $\mathrm{S}-$ (counterbalanced for

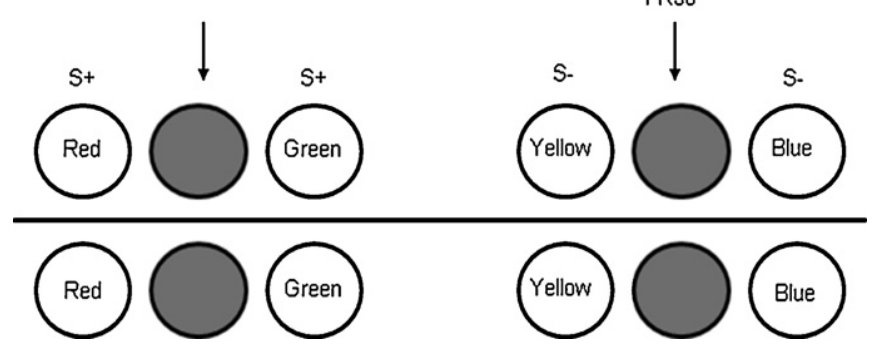

Fig. 3. A schematic of the different test trials. Following an initial FR1 event (top), an initial FR30 event (middle), or no initial event (bottom), pigeons were given a choice between the two $\mathrm{S}+$ stimuli from training or the two $\mathrm{S}-$ stimuli from training.

hue), resulted in the ITI alone. Completion of the FR30 on the center white key was followed by the illumination of the remaining two hues on the side keys. Again, choice of the $S+$ was followed by reinforcement and the ITI. Choice of the S- resulted in the ITI alone. The side key on which the correct stimulus appeared was counterbalanced over trials. There were 96 trials per session, 48 involving the FR1 initial event, 48 involving the FR30 initial event.

Each pigeon was trained in this way until it reached a criterion of $90 \%$ correct or better on both of the simultaneous discriminations for two consecutive sessions.

\subsubsection{Testing}

The first test session occurred on the session following attainment of criterion on the simultaneous discriminations. Test sessions consisted of 80 trials, 32 training trials (16 FR1 trials and 16 FR30 trials), and 48 preference trials. There were six kinds of test trials, three that involved a choice between the two S+ stimuli and three that involved a choice between the two $\mathrm{S}-$ stimuli. Each test trial could be preceded by an FR1 response requirement, an FR30 response requirement, or no pecking requirement, eight trials each (see Fig. 3 for the design of the test trials). Choice on test trials was defined by a single peck and was followed by nondifferential reinforcement on either $100 \%$ or $50 \%$ of the trials regardless of the pigeons' choice. Each pigeon received a total of 10 test sessions. Each test session was followed by 10 additional training sessions prior to the next test session. pigeons. Pigeons received either $100 \%$ or $50 \%$ reinforcement in training, and $100 \%$ or $50 \%$ reinforcement in testing. The groups were designated 100/100, 100/50, 50/100, and 50/50.

\section{Results}

\subsection{Training}

Overall, mean sessions to criterion in training was $4.50 \pm 0.83$ (mean \pm SEM). The 50/50 group reached criterion in $7.25 \pm 2.99$ sessions, the $50 / 100$ group in $4.50 \pm 1.29$ sessions, the $100 / 50$ group in
Thus, there were four experimental conditions, each with four 


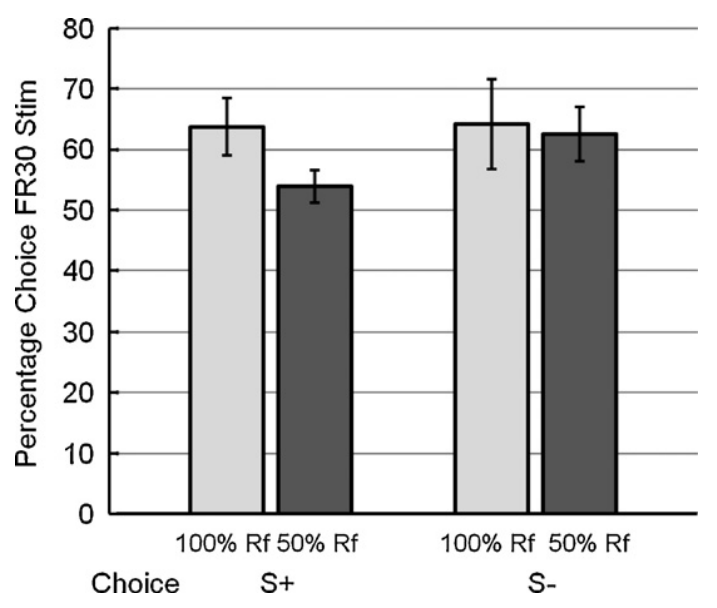

Fig. 4. Preference for the $S+$ (left) and $S-$ (right) associated with the FR30 initial event for pigeons trained with $100 \%$ or $50 \%$ reinforcement, pooled over the initial event in testing (FR30, FR1, or no initial event).

$3.00 \pm 0.82$ sessions, and the $100 / 100$ group in $3.25 \pm 1.26$ sessions. A two-way mixed-effect analysis of variance (ANOVA) performed on the sessions-to-criterion-in-training data, with percentage reinforcement (100\% vs. $50 \%$ ) as the independent groups factor and fixed ratio response requirement (FR30 vs. FR1) as the repeated measure, indicated that the effect of 50\% reinforcement (5.88 sessions) vs. 100\% reinforcement (3.12 sessions) approached but did not reach statistical significance, $F(1,7)=4.76, p=.065$, and neither the effect of fixed ratio, nor the percentage reinforcement $\times$ fixed ratio interaction was statistically significant, $F(1,7)=1.39, p=.28$, $F(1,7)=1.83, p=.22$, respectively.

\subsection{Testing}

\subsubsection{Preference for $S+F R 30$ on test trials}

A three-way ANOVA performed on the preference for the S+FR30 on choice trials, with percentage reinforcement (100\% vs. $50 \%$ ) during training, percentage reinforcement (100\% vs. 50\%) during testing, and the initial event during testing (FR30, FR1, or no event) as the three factors, indicated that the effect of percentage reinforcement during testing and all of the interactions involving this variable were not statistically significant, all $\mathrm{Fs}<1$, so this variable was not examined in further analyses.

On test trials in which pigeons chose between the S+FR1 and S+FR30 stimulus, the $\mathrm{S}+\mathrm{FR} 30$ stimulus was chosen on $63.8 \%( \pm 4.65)$ of the trials by pigeons trained with $100 \%$ reinforcement and $53.9 \%$ $( \pm 2.71)$ of the trials by pigeons trained with $50 \%$ reinforcement (see left side of Fig. 4). Although there was a significant preference for S+FR30 for pigeons trained with $100 \%$ reinforcement, $t(7)=2.96$, $p=.02$, the preference for S+FR30 for pigeons trained with $50 \%$ reinforcement was not statistically reliable, $t(7)=1.42, p>.05$. The difference in preference for the S+FR30 stimulus between pigeons trained with $100 \%$ reinforcement vs. those trained with $50 \%$ reinforcement, approached but did not reach statistical significance, $t(14)=1.84, p=.09$.

Because the $S+$ stimulus preference was expected to increase with training, preference for the S+FR30 was examined over the last two test sessions. Again, although there was a significant preference for S+FR30 for pigeons trained with $100 \%$ reinforcement, $t(7)=3.03, p=.02$, the preference for S+FR30 for pigeons trained with $50 \%$ reinforcement was not statistically reliable, $t(7)=1.23$, $p>.05$.

Arantes and Grace (2008) have argued that our method of calculating the preference for the $\mathrm{S}+$ followed by the less preferred schedule on test trials is biased because we test our pigeons with three different initial events, FR30, FR1, and no initial event. They argued that if the pigeons show any tendency to use the initial event as a conditional stimulus, the presumed similarity between FR1 and no initial event would bias this procedure against finding an effect (i.e., only $1 / 3$ rd of the trials would involve the high effort initial event). For this reason we repeated the preference-test analyses without the no initial event test trials. Once again, there was a significant preference for $\mathrm{S}+\mathrm{FR} 30$ for pigeons trained with $100 \%$ reinforcement, $65.1 \pm 5.00 \%, t(7)=3.02, p=.02$ and now the preference for S+FR30 for pigeons trained with $50 \%$ reinforcement, $56.6 \pm 2.78 \%$, was also statistically reliable, $t(7)=2.38, p=.05$. But again, the difference in preference for the S+FR30 stimulus between pigeons trained with $100 \%$ reinforcement vs. those trained with $50 \%$ reinforcement did not reach statistical significance $t(14)=1.48$, $p=.16$.

\subsubsection{Preference for $S-F R 30$ on test trials}

A similar three-way ANOVA performed on the S-FR30 choice test data with percentage reinforcement (100\% vs. 50\%) during training, percentage reinforcement (100\% vs. 50\%) during testing, and the initial event during testing (FR30, FR1, or no event) as the three factors indicated that the effect of percentage reinforcement during testing and all of the interactions involving this variable were not statistically significant, all Fs $<1$, so this variable was not examined in further analyses.

On test trials in which pigeons chose between the S-FR1 and S-FR30 stimulus, the S-FR30 stimulus was chosen on $64.2 \%( \pm 7.42)$ of the trials for pigeons trained with $100 \%$ reinforcement and $62.6 \%$ $( \pm 4.42)$ of the trials by pigeons trained with $50 \%$ reinforcement (see right side of Fig. 4). For pigeons trained with $100 \%$ reinforcement, although the preference for the $\mathrm{S}$ - associated with the FR30 initial event in training was comparable in magnitude to the $\mathrm{S}+$ associated with the FR30 initial event in training, because of high variability among the pigeons in this group, the effect was only marginally significant, $t(7)=2.05, p=.08$. On the other hand, for pigeons trained with $50 \%$ reinforcement, because the within-group variability was somewhat less, the preference for the S- associated with the FR30 initial event in training was statistically significant, $t(7)=2.84, p=.01$.

Once again, these analyses were repeated without the no initial event test trials and for the group trained with $100 \%$ reinforcement there was preference for the S- associated with the FR30 initial event in training, $68.1 \%( \pm 6.78)$ and now it too was statistically reliable, $t(7)=2.32, p=.05$, as was the preference for the $S$ - associated with the FR30 initial event in training for the group trained with $50 \%$ reinforcement, $64.5 \%( \pm 3.39), t(7)=4.27, p<.01$.

\subsubsection{Effect on $S+$ preference of the initial event on test trials}

A three-way mixed-effect ANOVA performed on the S+ test data with percentage reinforcement in training (50\% vs. $100 \%$ ), and percentage reinforcement in testing (50\% vs. $100 \%$ ) as independent factors, and initial event on test trials (FR30, FR1, and no initial event) as repeated measures indicated that there was a significant effect of the initial stimulus on test trials, $F(2,14)=26.39, p<.01$, but no other effect was statistically reliable, all Fs $<1$

The effect of the initial event on S+ test trials for the groups trained with $50 \%$ and $100 \%$ reinforcement appear in Fig. 5. As can be seen in Fig. 5 , in both conditions the preference for the S+ associated with the FR30 initial event was greatest on trials on which the initial event was the FR30 response requirement. The effect of the initial event on $\mathrm{S}+$ test trials was statistically significant for both the groups trained with $100 \%$ reinforcement, $F(2,21)=3.57, p=.046$ and the groups trained with $50 \%$ reinforcement, $F(2,21)=4.60, p=.022$, as indicated by separate one-way repeated-measures ANOVAs. Thus, on test trials, the initial event appeared to act as a conditional stimulus to choose the comparison stimulus because the preference for 

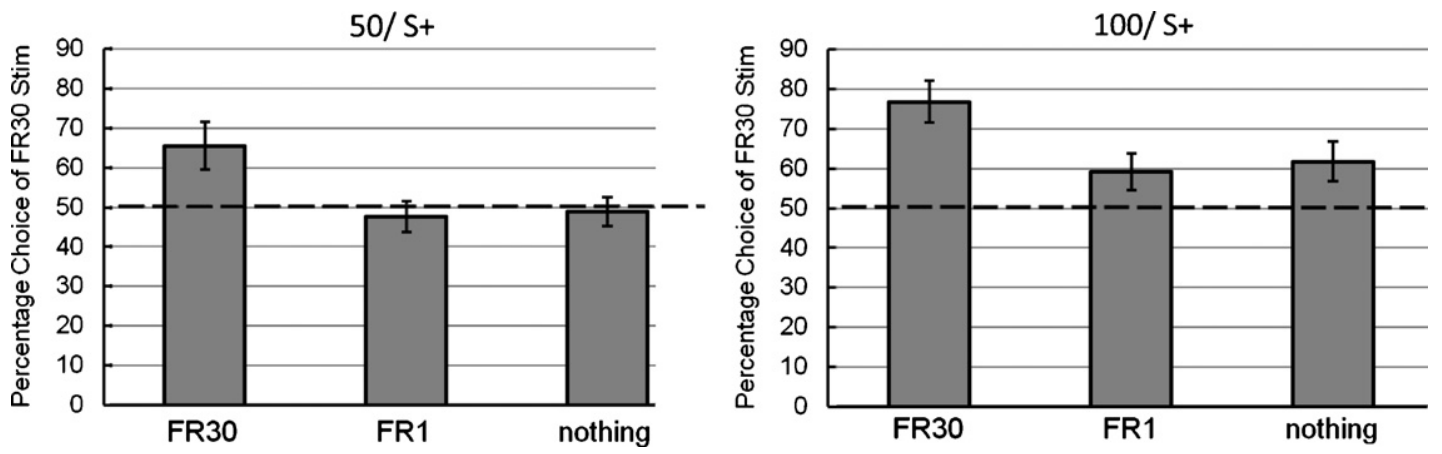

Fig. 5. Preference for the $S+$ associated with greater effort (FR30) in training as a function of the initial event on test trials (FR30, FR1, or no initial event) for pigeons trained with $50 \%$ reinforcement for correct choice (left) or $100 \%$ reinforcement for correct choice (right).
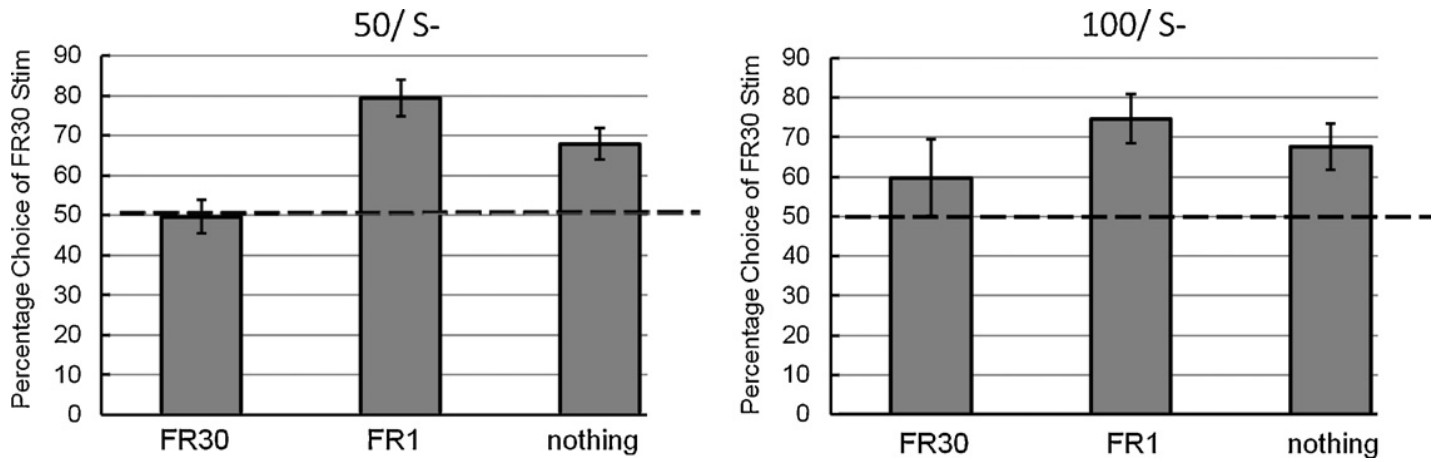

Fig. 6. Preference for the S- associated with greater effort (FR30) in training as a function of the initial event on test trials (FR30, FR1, or no initial event) for pigeons trained with $50 \%$ reinforcement for correct choice (left) or $100 \%$ reinforcement for correct choice (right).

the $\mathrm{S}+$ associated in training with the FR30 initial event was greatest when the initial event on test trials was the FR30.

\subsubsection{Effect on $S$ - preference of the initial stimulus on test trials}

A similar three-way ANOVA performed on the S- test data with percentage reinforcement in training ( $50 \%$ vs. $100 \%$ ) and percentage reinforcement in testing ( $50 \%$ vs. $100 \%$ ) as the independent factors, and the initial event on test trials (FR30, FR1, and no initial event) as the repeated measure indicated that there was a significant effect of the initial stimulus on test trials, $F(2,14)=57.93, p<.01$, but no other effect was statistically reliable, all Fs $<1$.

The effect of the initial event on $\mathrm{S}$ - test trials for the groups trained with $50 \%$ and $100 \%$ reinforcement appear in Fig. 6. As can be seen in Fig. 6 , in both conditions the preference for the $S$ - associated with the FR30 initial event was highest on trials on which the initial event was the FR1 response requirement. Again, the effect of the initial event on $\mathrm{S}$ - test trials was statistically significant for the groups trained with $50 \%$ reinforcement, $F(2,21)=12.51, p<.01$ but it was not statistically significant for the groups trained with $100 \%$ reinforcement, $F(2,21)=1.02, p>.05$, as indicated by separate one-way repeated-measures ANOVAs. However, the pattern of results was similar in both conditions. Again, in both conditions, the initial events appeared to act as a conditional stimulus but for these tests the preference for the $\mathrm{S}$ - associated in training with the FR30 initial event was least when the initial event on test trials was the FR30. In this case, it appears that the pigeons tended to use the initial event to avoid the $\mathrm{S}$ - associated with that event in training.

It should be noted that the effects of the initial events on the preferences for $\mathrm{S}+$ and $\mathrm{S}$ - stimuli were independent of the overall effect of preference for the S+ and S- associated with the FR30 initial event relative to chance. That is, these conditional effects of the initial stimulus on test trials cannot account for the within-trial contrast effects reported earlier.
One of the variables that appear to play a role in the development of within-trial contrast is the number of training sessions. In the present experiment we trained for over 100 sessions, with test sessions interspersed among training sessions. Although there appeared to be no clear trend over test sessions in the degree of preference for the S+ or S- associated with the FR30 initial event, as can be seen in Fig. 7, for the 100\% reinforcement group, choice of the S+ associated with the FR30 initial event started at $58 \%$ and rose to $68 \%$ on Testing Session 4 . For the $50 \%$ reinforcement group, choice of the S+ associated with the FR30 initial event started at $47 \%$ and rose to $59 \%$ on Testing Session 3. Thus, the preference does develop over the first few test sessions (each separated by 10 additional training sessions). The relative instability of those scores may

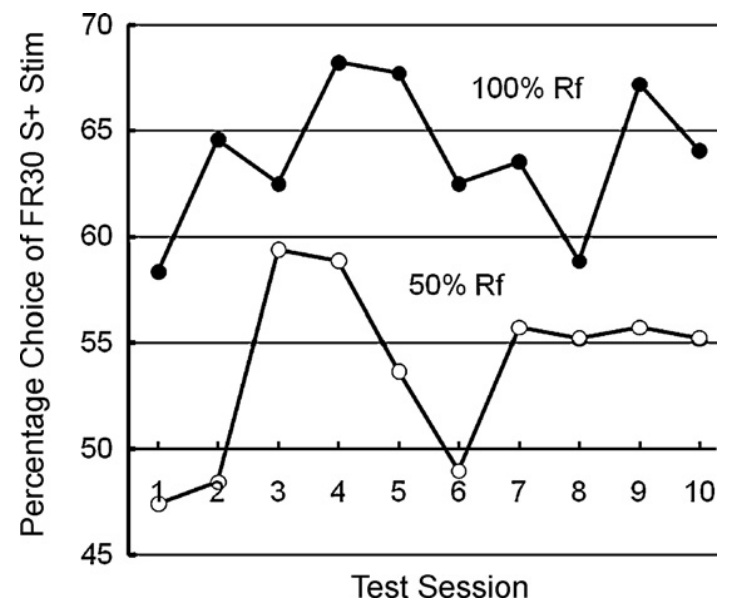

Fig. 7. Preference for the S+ stimulus associated with the FR30 initial event as a function of test session, pooled over the initial event on test trials (FR30, FR1, no initial event). 


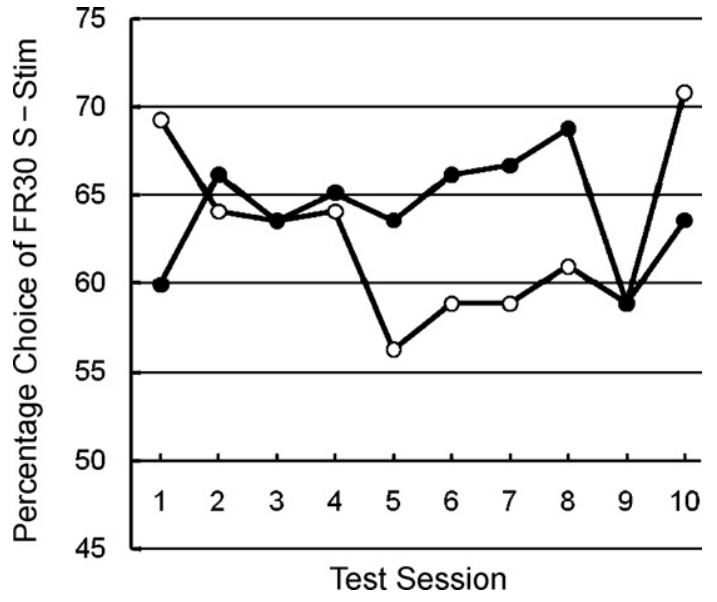

Fig. 8. Preference for the $\mathrm{S}-$ stimulus associated with the FR30 initial event as a function of test session, pooled over the initial event on test trials (FR30, FR1, no initial event).

be because there were only $24 \mathrm{~S}+$ test trials in each test session for each pigeon.

The comparable data for $\mathrm{S}-$ test trials appear in Fig. 8. For the $100 \%$ reinforcement group choice of the $S$ - associated with the FR3 initial event started at $60 \%$ and rose to $69 \%$ on Testing Session 8 . The $\mathrm{S}$ - preference data for the $50 \%$ reinforcement group were less systematic. Preference for the S- associated with the FR30 initial event started at $69 \%$ and dropped to a low of $56 \%$ on Test Session 5 before rising again to a high of $71 \%$ on Testing Session 10 .

\section{Discussion}

\section{1. $S+$ preference}

To test the model of within-trial contrast effect proposed by Clement et al. (2000) we trained a group of pigeons with $50 \%$ reinforcement. According to that model, if preference for the S+ stimulus associated with a greater pecking requirement resulted from the ratio of the difference in value between high effort and reinforcement to the difference in value between low effort and reinforcement (see Fig. 1), then reducing the value of the reinforcer for both differences should magnify the relative difference (or ratio between differences) in contrast between the high and low effort response.

Alternatively, if there is a threshold for the difference between effort and reinforcement below which contrast will not be found, it may be that $50 \%$ reinforcement is insufficient to produce contrast. The results indicated that an overall within-trial contrast effect was found for the S+ stimuli for the groups trained with $100 \%$ reinforcement. However, a significant within-trial contrast effect was found for the S+ stimuli for the groups trained with $50 \%$ reinforcement only when the initial event on test trials was one of the training values (FR30 or FR1). Thus, it appears that 50\% reinforcement does not produce greater contrast between FR1 and FR30 than 100\% reinforcement. In fact, although the difference between 100\% reinforcement and 50\% reinforcement was not significant, it appears that the overall preference for the S+ associated with the FR30 initial event in training was somewhat less for the groups trained with $50 \%$ reinforcement than those trained with $100 \%$ reinforcement.

It is not clear why there was not a significant preference for the for the S+ associated with the FR30 initial event when reinforcement for correct choice of the S+ was only $50 \%$ but the within-trial contrast effect has typically appeared as only a $60-70 \%$ preference for the $\mathrm{S}+$ that follows the least preferred initial event. Thus, although there were 16 pigeons in the experiment and the effect of percentage of reinforcement during testing was not statistically reliable, it meant that there were only four pigeons in each of the four conditions. It may be that the small number of pigeons in each condition may have reduced the sensitivity of the statistical test to the effect of initial link FR manipulation. It also may be that although the percentage of reinforcement did not affect the contrast between the initial and terminal links, it may have affected the rate at which the association developed between the initial and terminal links (see Friedrich and Zentall, 2004; Singer et al., 2007). Although the number of training sessions may have been sufficient to observe a within-trial contrast effect with $100 \%$ reinforcement, it may take longer to develop such an effect with 50\% reinforcement (see Fig. 7).

A variable that has not yet been considered but might affect the magnitude of the within-trial contrast effect is the level of food restriction experienced by the pigeon prior to experimental sessions. Food restriction as a differential state associated with a distinctive stimulus that is followed by reinforcement has been shown to produce a contrast effect (Pompilio and Kacelnik, 2005; Pompilio et al., 2006; Vasconcelos and Urcuioli, 2008b). That is, animals prefer stimuli associated with food when they are more hungry over stimuli associated with food when they are less hungry. In the present context, if the motivation for food were greater, the pigeons might experience greater contrast upon the appearance of the terminal-link stimuli.

\section{2. $S$ - preference}

Interestingly, a within-trial contrast effect was found for the Sstimuli in both of the groups trained with $50 \%$ reinforcement. It also was found for the groups trained with $100 \%$ reinforcement, although it was statistically reliable only when the initial event on test trials was one of the training values. Clement et al. (2000) suggested that preference for the $\mathrm{S}$ - associated with the high effort response may be produced by value transfer from its associated S+ (see Fersen et al., 1991). But the fact that Clement et al. found a greater preference for the $\mathrm{S}$ - associated with the high effort response than the $\mathrm{S}+$ associated with the high effort response suggests that some additional factor must be involved.

In the present study, the initial event on test trials had a significant effect on choice of both the S+ and S- stimuli. The initial FR30 event significantly increased the preference for the $S+$ stimulus that in training followed it and significantly decreased the preference for the $\mathrm{S}$ - stimulus that in training followed it. This occurred is spite of the fact that, unlike a true conditional discrimination, in training, it was not necessary to use the initial event to correctly choose the S+.

Effects of the initial event from training on test trials have not always been found in research of this kind but when they have been reported, the effects were similar to those found in the present study. For example, DiGian et al. (2004) found that although there was an overall preference for the $\mathrm{S}+$ that in training was preceded by a delay (a nonpreferred event) over the $S+$ that was preceded by no delay, the preference was significantly greater on test trials on which a delay preceded the choice. However, as mentioned earlier, any general tendency to use the initial events on test trials as a conditional cue for choice of the S+ or S- stimuli should not selectively favor either S+ or S- stimulus when the data are combined.

A secondary, but perhaps as important, purpose of the present study was to replicate the within-trial contrast effect first reported by Clement et al. (2000), an effect that others have not always been able to replicate. As mentioned earlier, in several of those experiments, the pigeons may not have been provided sufficient training prior to testing (Vasconcelos et al., 2007) and prior experience with lean schedules of reinforcement may have reduced the aversiveness of the high effort response, thus reducing contrast in the study by Arantes and Grace (2008). But more recently Vasconcelos and 
Urcuioli (2009) failed to find a within-trial contract effect under more ideal training conditions.

Although within-trial contrast effects have been reported using various other less preferred events (added delay, the absence of food, additional travel time) to produce contrast, only one other published study (Friedrich and Zentall, 2004) has reported a withintrial contrast effect using a differential pecking requirement as the contrast producing prior event. Thus, the results of the present study offer support for the original within-trial contrast effect and argue against the conclusion proposed by Vasconcelos et al. (2007) and Arantes and Grace (2008), that the terminal-link contrast of the kind reported here is an example of a Type 1 statistical error. We expect that further research will be needed to clarify the conditions under which this kind of contrast effect can be reliably obtained.

\section{References}

Alessandri, J., Darcheville, J.-C., Zentall, T.R., 2008a. Cognitive dissonance in children justification of effort or contrast? Psychonomic Bulletin \& Review 15, 673-677.

Alessandri, J., Darcheville, J.-C., Delevoye-Turrell, Y., Zentall, T.R., 2008b. Preference for rewards that follow greater effort and greater delay. Learning \& Behavior 36 352-358

Arantes, J., Grace, R., 2008. Failure to obtain value enhancement by within-trial contrast in simultaneous and successive discrimination. Learning \& Behavior 36 (1) $1-11$.

Clement, T.S., Feltus, J.R., Kaiser, D.H., Zentall, T.R., 2000. Work ethic in pigeons: reward value is directly related to the effort or time required to obtain the reward. Psychonomic Bulletin \& Review 7 (1), 100-106.

Clement, T.R., Zentall, T.R., 2002. Second-order contrast based on the expectation of effort and reinforcement. Journal of Experimental Psychology: Animal Behavior Processes 28, 64-74.
Fersen, Lv., Wynne, C.D.L., Delius, J.D., Staddon, J.E.R., 1991. Transitive inference formation in pigeons. Journal of Experimental Psychology: Animal Behavior Processes 17, 334-341.

DiGian, K.A., Friedrich, A.M., Zentall, T.R., 2004. Reinforcers that follow a delay have added value for pigeons. Psychonomic Bulletin \& Review 11, 889-895.

Friedrich, A.M., Clement, T.S., Zentall, T.R., 2005. Reinforcers that follow the absence of reinforcement have added value for pigeons. Learning \& Behavior 33, 337-342.

Friedrich, A.M., Zentall, T.R., 2004. Pigeons shift their preference toward locations of food that take more effort to obtain. Behavioural Processes 67, 405-415.

Kacelnik, A., Marsh, B., 2002. Cost can increase preference in starlings. Animal Behaviour 63, 245-250.

Klein, E.D., Bhatt, R.S., Zentall, T.R., 2005. Contrast and the justification of effort Psychonomic Bulletin \& Review 12, 335-339.

Pompilio, L., Kacelnik, A., 2005. State-dependent learning and suboptimal choice: when starlings prefer long over short delays to food. Animal Behaviour 70 571-578.

Pompilio, L., Kacelnik, A., Behmer, S.T., 2006. State-dependent learned valuation drives choice in an invertibrate. Science 311, 1613-1615.

Singer, R.A., Berry, L.M., Zentall, T.R., 2007. Preference for a stimulus that follows a relatively aversive event: contrast or delay reduction? Journal of the Experimental Analysis of Behavior 87, 275-285.

Vasconcelos, M., Urcuioli, P.J., Lionello-DeNolf, K.M., 2007. Failure to replicate the "work ethic" effect in pigeons. Journal of the Experimental Analysis of Behavior 87, 383-399.

Vasconcelos, M., Urcuioli, P., 2008a. Certainties and mysteries in the within-trial contrast literature: a reply to Zentall. Learning \& Behavior 36, 23-25.

Vasconcelos, M., Urcuioli, P., 2008b. Deprivation level and choice in pigeons: a test of within-trial contrast. Learning \& Behavior 36, 12-18.

Vasconcelos, M., Urcuioli, P., 2009. Extensive training is insufficient to produce the work-ethic effect in pigeons. Journal of the Experimental Analysis of Behavior 91, 143-152.

Zentall, T.R., Singer, R.A., 2007. Within-trial contrast: when is a failure to replicate not a type I error? Journal of the Experimental Analysis of Behavior 87, 401-404.

Zentall, T.R., 2008. Within-trial contrast: when you see it and when you don't. Learning \& Behavior 36 (1), 19-22. 